\title{
Baseline Sensitivity and Cross-Resistance to Succinate-Dehydrogenase- Inhibiting and Demethylation-Inhibiting Fungicides in Didymella bryoniae
}

\author{
A. Thomas, D. B. Langston, Jr., and K. L. Stevenson, Department of Plant Pathology, University of Georgia, Tifton $31793-5766$
}

\begin{abstract}
Thomas, A., Langston, D. B., Jr., and Stevenson, K. L. 2012. Baseline sensitivity and cross-resistance to succinate-dehydrogenase-inhibiting and demethylation-inhibiting fungicides in Didymella bryoniae. Plant Dis. 96:979-984.

Didymella bryoniae, which causes gummy stem blight (GSB) of watermelon, has a history of developing resistance to fungicides, most recently the succinate-dehydrogenase-inhibiting (SDHI) fungicide boscalid. To facilitate fungicide resistance monitoring, baseline sensitivity distributions were established for demethylation-inhibiting (DMI) fungicides tebuconazole and difenoconazole and the SDHI fungicide penthiopyrad, and reestablished for the SDHI fungicide boscalid. In all, 71 isolates with no known prior exposure to SDHIs or DMIs were used to determine the effective concentration at which mycelial growth was inhibited by $50 \%\left(\mathrm{EC}_{50}\right)$. $\mathrm{EC}_{50}$ values for boscalid, penthiopyrad, tebuconazole, and difenoconazole were 0.018 to $0.064,0.015$ to 0.057 , 0.062 to 0.385 , and 0.018 to $0.048 \mu \mathrm{g} / \mathrm{ml}$, with median values of 0.032 ,

$0.026,0.118$, and $0.031 \mu \mathrm{g} / \mathrm{ml}$, respectively. Significant positive correlations between the sensitivity to penthiopyrad and boscalid $(P<$ $0.0001, r=0.75)$ and between tebuconazole and difenoconazole $(P<$ $0.0001, r=0.59)$ indicate a potential for cross-resistance between chemically related fungicides. In 2009, 103 isolates from fungicidetreated watermelon fields were tested for sensitivity to boscalid and penthiopyrad using a discriminatory concentration of $3.0 \mu \mathrm{g} / \mathrm{ml}$. Of the isolates tested, 82 were insensitive and 14 were sensitive to both fungicides. Because of the significant potential for cross-resistance between closely related fungicides, growers will be advised not to use both SDHIs or both DMIs successively in the same fungicide spray program.
\end{abstract}

Gummy stem blight (GSB), caused by the fungus Didymella bryoniae (Fuckel) Rehm (anamorph Phoma cucurbitacearum (Fr.) Sacc.), is the most destructive disease of watermelon in greenhouses $(1,43)$ and in the major watermelon-producing areas of the southeastern United States $(37,40)$. The disease can develop rapidly and cause significant yield reductions under warm and wet conditions (1). Management of GSB requires an integration of both cultural practices and chemical methods; however, cultural practices have limited effectiveness for GSB management. The most effective means of managing GSB is frequent application of fungicides. The protectant fungicide chlorothalonil (FRAC CODE-M5) is effective for GSB control but it can be applied only in the early part of the season because it can cause phytotoxicity on mature watermelon rinds (17). Because of the potential for the explosive development of GSB under conducive environmental conditions, use of systemic fungicides is usually necessary for the control GSB in the field.

During the first few years following the introduction of systemic fungicides for use on watermelons in the United States, they provided excellent control of GSB. However, D. bryoniae has shown a remarkable ability to adapt and become resistant to several of these systemic fungicides. D. bryoniae can be considered a high-risk pathogen for the development of resistance because it has a short life cycle and abundant sporulation which, in turn, demands a frequent application of fungicides for its management (5). Thiophanate-methyl, a fungicide in the methyl benzimidazole carbamate fungicide class (FRAC CODE-1), provided good control of GSB until resistance was observed in the early 1990s (20). In the late 1990s, the quinone-outside inhibitor (QoI) fungicide azoxystrobin (FRAC CODE-11) provided excellent control of GSB (19) and was granted section 18 Emergency Exemption in the 1998 growing season in Georgia to control GSB (40). However, soon after the

Corresponding author: K. L. Stevenson, E-mail: ks@uga.edu

Accepted for publication 18 January 2012.

http://dx.doi.org/10.1094/PDIS-09-11-0744-RE

(C) 2012 The American Phytopathological Society first commercial use of azoxystrobin, $D$. bryoniae isolates that were insensitive to azoxystrobin were found in Georgia, North Carolina, South Carolina, Delaware, and Maryland $(18,31,40)$. After development of resistance to azoxystrobin, a new fungicide, Pristine, which is a mixture of the QoI fungicide pyraclostrobin and boscalid, in the succinate-dehydrogenase-inhibiting (SDHI) class (FRAC CODE-7), showed good efficacy against GSB in the field (36). Isolates of $D$. bryoniae and other fungal pathogens that showed resistance against azoxystrobin were found to be sensitive to Pristine $(25,33)$. Thus, even pathogens that had developed resistance to azoxystrobin could be controlled by the boscalid component of Pristine (3). Pristine worked well against $D$. bryoniae until resistance to boscalid was observed in 2007 (39). A new SDHI fungicide, penthiopyrad, is currently being evaluated for its effectiveness in managing GSB in experimental plots in Georgia.

Demethylation-inhibiting (DMI) fungicides (FRAC CODE-3), introduced in the 1970s, have a broad spectrum of activity against different fungal pathogens and are being used for the management of a number of plant diseases (5). Although DMI fungicides have been around for a while, they were labeled for use on cucurbits for managing GSB only recently, in 2008. Tebuconazole (labeled in 2008) and difenoconazole (labeled in 2010), belonging to the DMI group, are the only two registered systemic fungicides against which no resistance in $D$. bryoniae has been reported from Georgia thus far. However, resistance to DMIs has been reported in many other ascomycete fungi, including Monilinia fructicola, Venturia inaequalis, Mycosphaerella graminicola, and several powdery mildew pathogens $(9,21,26,32)$. Increased reliance on DMI fungicides for management of GSB will increase selection pressure and the risk of resistance development in populations of $D$. bryoniae. Also, because $D$. bryoniae has a history of rapidly developing resistance to fungicides with single-site mode of action $(20,31,39,40)$, it is important to establish the baseline sensitivity of $D$. bryoniae to effective fungicides and initiate monitoring programs to detect any significant change in pathogen sensitivity that might lead to a disease control failure.

Knowledge about the occurrence of cross-resistance among fungicides is important in selecting appropriate combinations of fungicides for GSB management programs. Cross-resistance 
Table 1. Source of isolates of Didymella bryoniae obtained from infected watermelon leaves collected in 2001 or 2002 from fields in Georgia used to determine baseline sensitivities to boscalid and penthiopyrad

\begin{tabular}{|c|c|}
\hline Isolate $^{\mathrm{a}}$ & Georgia county \\
\hline Gate-5 & Telfair \\
\hline Gate-6 & Telfair \\
\hline Gate-10 & Telfair \\
\hline Gs2-1 & Dooly \\
\hline Gs2-2 & Dooly \\
\hline Gs2-3 & Dooly \\
\hline Gs2-4 & Dooly \\
\hline Gs2-5 & Dooly \\
\hline Gs2-6 & Dooly \\
\hline Gs2-10 & Dooly \\
\hline Gs2-11 & Dooly \\
\hline Gs2-12 & Dooly \\
\hline Gs4-1 & Cook \\
\hline Gs4-3 & Cook \\
\hline Gs4-6 & Cook \\
\hline Gs4-7 & Cook \\
\hline Gs4-8 & Cook \\
\hline Gs4-9 & Cook \\
\hline Gs4-10 & Cook \\
\hline Gs4-12 & Cook \\
\hline Gs12-1 & Decatur \\
\hline Gs12-4 & Decatur \\
\hline Gs12-5b & Decatur \\
\hline Gs12-10a & Decatur \\
\hline Gs12-30 & Decatur \\
\hline Gs14-4 & Tift \\
\hline Gs14-5 & Tift \\
\hline Gs14-6 & Tift \\
\hline Gs14-8 & Tift \\
\hline Gs14-20 & Tift \\
\hline Gs14-21 & Tift \\
\hline Gs14-37 & Tift \\
\hline Gs15-5 & Cook \\
\hline Gs15-6 & Cook \\
\hline Gs15-8 & Cook \\
\hline Gs15-11 & Cook \\
\hline Gs $15-12$ & Cook \\
\hline Gs15-14 & Cook \\
\hline Gs15-21 & Cook \\
\hline Gs15-22 & Cook \\
\hline Gs $15-23$ & Cook \\
\hline Gs15-25 & Cook \\
\hline Gs $15-28$ & Cook \\
\hline Gs15-33 & Cook \\
\hline Gs15-34 & Cook \\
\hline Gs6-1 & Worth \\
\hline Gs6-2 & Worth \\
\hline Gs6-3 & Worth \\
\hline Gs6-4 & Worth \\
\hline Gs6-5 & Worth \\
\hline Gs6-6 & Worth \\
\hline Gs6-7 & Worth \\
\hline Gs6-9 & Worth \\
\hline Gs6-10 & Worth \\
\hline Gs9-1 & Tift \\
\hline Gs9-2 & Tift \\
\hline Gs9-3 & Tift \\
\hline Gs9-4 & Tift \\
\hline Gs9-5 & Tift \\
\hline Gs9-6 & Tift \\
\hline Gs9-7 & Tift \\
\hline Gs9-9 & Tift \\
\hline Gs9-10 & Tift \\
\hline Gs9-11 & Tift \\
\hline Gs9-12 & Tift \\
\hline Gs9-13 & Tift \\
\hline Gs9-14 & Tift \\
\hline Gs9-16 & Tift \\
\hline Gs9-17 & Tift \\
\hline Gs9-19 & Tift \\
\hline Gs9-20 & Tift \\
\hline
\end{tabular}

${ }^{a}$ Isolates Gate-5, Gate-6, and Gate-10 were collected in 2001. All other isolates were collected in 2002. among fungicides within the same group has been reported previously in many fungi $(3,12,13,16,22)$. Penthiopyrad belongs to the same cross-resistance group as boscalid and, because cross-resistance to boscalid and penthiopyrad has been reported previously in other fungi $(3,13)$, it is important to evaluate the effectiveness of penthiopyrad in controlling boscalid-resistant isolates of $D$. bryoniae in Georgia. Tebuconazole and difenoconazole (one component of Inspire Super) belong to the same triazole class of DMI fungicides. Because these two are the only effective systemic fungicides available to watermelon growers in the United States, it is important to evaluate the feasibility of using these two fungicides as rotation partners for managing GSB. This study was designed to provide critical information about the baseline sensitivity of $D$. bryoniae and the potential for development of cross resistance between the DMI fungicides. The objectives were to (i) determine the baseline sensitivity of $D$. bryoniae to penthiopyrad, tebuconazole, and difenoconazole and select a discriminatory concentration for routine sensitivity monitoring; (ii) assess the potential for cross-resistance between tebuconazole and difenoconazole and between penthiopyrad and boscalid in D. bryoniae; and (iii) investigate the cross-resistance pattern between boscalid and penthiopyrad in isolates of $D$. bryoniae collected from commercial watermelon production fields in 2009 , where boscalid failed to control GSB.

\section{Materials and Methods}

Determination of baseline fungicide sensitivity. In all, 71 single-lesion isolates of $D$. bryoniae that were never exposed to either DMI or SDHI fungicides were used to determine the baseline sensitivity to penthiopyrad, tebuconazole, and difenoconazole. These isolates were originally obtained from watermelon leaves with symptoms of GSB collected in 2001 or 2002 from different counties in Georgia (Table 1). The isolates were stored on filter paper at $-20^{\circ} \mathrm{C}$ until needed. Stored isolates were recovered by placing a piece of filter paper with fungal mycelium on a fresh plate of potato dextrose agar (PDA) and incubating it at $25^{\circ} \mathrm{C}$ for 7 days in preparation for fungicide sensitivity assays. Technicalgrade boscalid (98.4\% a.i.; BASF Corporation, Research Triangle Park, NC), penthiopyrad (99\% a.i.; E. I. du Pont de Nemours \& Co., Wilmington, DE), tebuconazole (97.5\% a.i.; Bayer Corporation, Kansas City, MO), and difenoconazole (95\% a.i.; Syngenta Crop Protection, Greensboro, NC) were dissolved in acetone to obtain stock solutions of $30 \mathrm{mg} / \mathrm{ml}$. Serial dilutions of the stock solution of each fungicide were made in acetone and added to autoclaved PDA, then cooled to $55^{\circ} \mathrm{C}$ to obtain desired concentrations of $0,0.0001,0.001,0.003,0.01,0.03,0.1,0.3,1.0$, and 3.0 $\mu \mathrm{g} / \mathrm{ml}$. The final concentration of acetone in fungicide-amended and nonamended medium (acetone only) was $0.1 \%$ by volume.

Sensitivity of each isolate to tebuconazole, difenoconazole, penthiopyrad, and boscalid was determined by using an in vitro mycelial growth assay on fungicide-amended and nonamended (acetone only) PDA. Mycelial plugs, $6 \mathrm{~mm}$ in diameter and taken from the margin of a 1-week-old culture on PDA, were placed upside down in the center of fungicide-amended and nonamended PDA plates. Two replications of each isolate and fungicide concentration were prepared. After 4 days of incubation in the dark at $25^{\circ} \mathrm{C}$, the diameter of each colony was measured and corrected by subtracting the diameter of the mycelial plug. Relative growth (RG) was calculated as the ratio between the corrected colony diameter on fungicide-amended medium and the corrected colony diameter on nonamended medium.

Investigation of cross resistance among SDHI fungicides. Watermelon leaves with symptoms of GSB were collected from fungicide-treated and nontreated watermelon fields in Georgia, North Carolina, and South Carolina in 2009. A small section of tissue, approximately $0.25 \mathrm{~cm}^{2}$, was cut from the margin of one lesion on each leaf. The tissue pieces were surface disinfested with $0.6 \%$ $\mathrm{NaOCl}$, rinsed in sterile water, placed onto PDA amended with antibiotics (tetracycline, chloramphenicol, and streptomycin, each at $50 \mu \mathrm{g} / \mathrm{ml}$ ), incubated at $25^{\circ} \mathrm{C}$ for 5 days, and subsequently trans- 
ferred to PDA to obtain a pure culture. Fungal colonies were identified as D. bryoniae based on the morphological characteristics of the colony on PDA. In total, 103 single-lesion isolates of $D$. bryoniae were obtained.

Sensitivity of the isolates to boscalid and penthiopyrad was determined using an in vitro mycelial growth assay on PDA amended with fungicides at a discriminatory concentration of 3.0 $\mu \mathrm{g} / \mathrm{ml}$. This discriminatory concentration was selected based on previous work with isolates of $D$. bryoniae collected from fields where boscalid failed to control GSB. These isolates grew well on medium amended with boscalid at $3.0 \mu \mathrm{g} / \mathrm{ml}$, whereas the sensitive isolates from storage (not previously exposed to SDHIs) were unable to grow with boscalid at $3.0 \mu \mathrm{g} / \mathrm{ml}$ or even $1.0 \mu \mathrm{g} / \mathrm{ml}$. Technical-grade boscalid (BASF Corporation) or penthiopyrad (E. I. du Pont de Nemours \& Co.) was dissolved in acetone to obtain a stock solution of $30 \mathrm{mg} / \mathrm{ml}$. A 10 -fold dilution of the stock solution was prepared in acetone and added to autoclaved PDA cooled to $55^{\circ} \mathrm{C}$ to obtain the desired concentration of $3.0 \mu \mathrm{g} / \mathrm{ml}$ in the medium. Control medium was prepared by adding acetone to autoclaved and cooled PDA, such that the final concentration of acetone in fungicide-amended and nonamended medium (acetone only) was $0.1 \%$ by volume. Isolates were transferred to fungicide-amended and nonamended medium, incubated, and measured as described above. Isolates with an RG value greater than 0.2 were considered insensitive to the respective fungicide. A contingency table was prepared to record the number of sensitive and resistant isolates to both fungicides.

Statistical analysis. The effective concentration at which mycelial growth was inhibited by $50 \%\left(\mathrm{EC}_{50}\right)$ value for each isolate was estimated based on linear regression of probit-transformed relative inhibition $(1-R G)$ on $\log _{10}$-transformed fungicide concentration. The frequency distribution of $\mathrm{EC}_{50}$ for each fungicide was tested for normality using the Shapiro-Wilk test (PROC UNIVARIATE) in SAS (version 9.2; SAS Institute Inc., Cary, NC). Paired $t$ tests were performed to compare the mean $\log _{10}$-transformed $\mathrm{EC}_{50}$ values among experimental repeats. The coefficient of variability (standard error/mean) of $\log _{10}$-transformed $\mathrm{EC}_{50}$ values for individual isolates among all experimental repeats was calculated as a measure of assay reproducibility. A discriminatory concentration for each fungicide was selected based on the frequency distribution of $\mathrm{EC}_{50}$ values. A concentration at which complete inhibition of the growth of a sensitive isolate was observed was selected as the discriminatory concentration for penthiopyrad. A concentration at which a significant difference in RG could be detected between a sensitive and a reduced-sensitive isolate was selected as discriminatory concentration for the DMI fungicides. A concentration closer to the mean $\mathrm{EC}_{50}$ could be chosen to detect a small shift in sensitivity and, because this small shift in sensitivity usually does not necessarily translate to a loss of control in the field, a discriminatory concentration well above the mean $\mathrm{EC}_{50}$ was chosen as the discriminatory concentration for monitoring purposes in this study (38). Simple linear correlation coefficients were calculated (PROC CORR) to determine the relationship between the sensitivity to (i) boscalid and penthiopyrad and (ii) tebuconazole and difenoconazole, and to evaluate the potential for cross-resistance within SDHI and DMI fungicides (34). Fisher's exact test was performed to test for a positive relationship between sensitivity to boscalid and penthiopyrad.

\section{Results}

Baseline fungicide sensitivity distributions. Coefficients of variation of $\log _{10}$-transformed $\mathrm{EC}_{50}$ values of individual isolates among experimental repeats were 0.7 to $9.0 \%$ for penthiopyrad, 0.2 to $11.0 \%$ for boscalid, 1.2 to $19.0 \%$ for tebuconazole, and 0.8 to $9.4 \%$ for difenoconazole (Table 2). The coefficient of variation was less than $20 \%$ for all fungicides tested, which indicates that the $\log _{10}$-transformed $\mathrm{EC}_{50}$ values for individual isolates were consistent among the experimental repeats. Therefore, data from individual experimental repeats were combined to determine the mean $\mathrm{EC}_{50}$ value for each isolate and fungicide (Table 2). Frequency distributions of mean $\mathrm{EC}_{50}$ values were log-normal for penthiopy$\operatorname{rad}([\operatorname{Pr}<\mathrm{W}]=0.87)$, boscalid $([\mathrm{Pr}<\mathrm{W}]=0.95)$, and difenoconazole $([\mathrm{Pr}<\mathrm{W}]=0.43)$ but was not log-normal for tebuconazole $([\operatorname{Pr}<\mathrm{W}]<0.0001) . \mathrm{EC}_{50}$ values for isolates exposed to penthiopyrad were 0.015 to $0.057 \mu \mathrm{g} / \mathrm{ml}$ and the median $\mathrm{EC}_{50}$ value was $0.026 \mu \mathrm{g} / \mathrm{ml}$ (Fig. 1A; Table 2). For boscalid, the $\mathrm{EC}_{50}$ values were 0.018 to $0.064 \mu \mathrm{g} / \mathrm{ml}$ and the median $\mathrm{EC}_{50}$ value was $0.032 \mu \mathrm{g} / \mathrm{ml}$ (Fig. 1B; Table 2). For tebuconazole, $\mathrm{EC}_{50}$ values were 0.062 to $0.385 \mu \mathrm{g} / \mathrm{ml}$ and the median $\mathrm{EC}_{50}$ value was $0.118 \mu \mathrm{g} / \mathrm{ml}$ (Fig. $2 \mathrm{~A}$; Table 2). For difenoconazole, $\mathrm{EC}_{50}$ values were 0.018 to 0.048 $\mu \mathrm{g} / \mathrm{ml}$ and the median $\mathrm{EC}_{50}$ value was $0.031 \mu \mathrm{g} / \mathrm{ml}$ (Fig. 2B; Table 2). A discriminatory concentration of $3.0 \mu \mathrm{g} / \mathrm{ml}$ was chosen for penthiopyrad, boscalid, tebuconazole, and difenoconazole fungicides for use in future sensitivity monitoring studies (Table 2).

There were significant positive correlations of $\mathrm{EC}_{50}$ values between penthiopyrad and boscalid and between tebuconazole and difenoconazole among the baseline isolates in all experimental repeats. The correlation coefficients were 0.59 to 0.72 for penthiopyrad and boscalid and 0.39 to 0.66 for tebuconazole and difenoconazole. The relationship between sensitivity to the two SDHIs (Fig. 3) and DMIs (Fig. 4) for the combined data is provided.

Cross-sensitivity assay. Of the 103 single-lesion isolates tested, 82 isolates were insensitive to both boscalid and penthiopyrad, 14 isolates were sensitive to both fungicides, and 7 isolates were

Table 2. Range, mean, and median effective concentration at which mycelial growth was inhibited by $50 \%$ ( $\left.\mathrm{EC}_{50}\right)$ values and coefficient of variability based on $\log _{10}$-transformed $\mathrm{EC}_{50}$ values of baseline isolates of Didymella bryoniae for each fungicide

\begin{tabular}{|c|c|c|c|c|c|}
\hline \multirow[b]{2}{*}{ Fungicide } & \multirow[b]{2}{*}{ Experiment } & \multicolumn{3}{|c|}{$\mathrm{EC}_{50}(\mu \mathrm{g} / \mathrm{ml})$} & \multirow[b]{2}{*}{ Coefficient of variability } \\
\hline & & Range & Mean & Median & \\
\hline \multirow[t]{4}{*}{ Penthiopyrad } & 1 & $0.016-0.064$ & 0.033 & 0.030 & $0.007-0.093$ \\
\hline & 2 & $0.010-0.085$ & 0.027 & 0.026 & $\ldots$ \\
\hline & 3 & $0.011-0.061$ & 0.027 & 0.026 & $\ldots$ \\
\hline & Combined & $0.015-0.057$ & 0.028 & 0.026 & $\ldots$ \\
\hline \multirow[t]{4}{*}{ Boscalid } & 1 & $0.017-0.098$ & 0.041 & 0.040 & $0.002-0.112$ \\
\hline & 2 & $0.015-0.087$ & 0.033 & 0.029 & $\ldots$ \\
\hline & 3 & $0.015-0.079$ & 0.033 & 0.032 & $\ldots$ \\
\hline & Combined & $0.018-0.064$ & 0.034 & 0.032 & $\ldots$ \\
\hline \multirow[t]{4}{*}{ Tebuconazole } & 1 & $0.084-0.388$ & 0.143 & 0.134 & $0.012-0.186$ \\
\hline & 2 & $0.060-0.483$ & 0.128 & 0.109 & $\ldots$ \\
\hline & 3 & $0.031-0.306$ & 0.113 & 0.109 & $\ldots$ \\
\hline & Combined & $0.062-0.385$ & 0.124 & 0.118 & $\ldots$ \\
\hline \multirow[t]{4}{*}{ Difenoconazole } & 1 & $0.016-0.078$ & 0.044 & 0.045 & $0.008-0.094$ \\
\hline & 2 & $0.013-0.055$ & 0.031 & 0.029 & $\ldots$ \\
\hline & 3 & $0.012-0.057$ & 0.025 & 0.024 & $\ldots$ \\
\hline & Combined & $0.018-0.048$ & 0.032 & 0.031 & $\ldots$ \\
\hline
\end{tabular}

\footnotetext{
${ }^{a}$ Coefficient of variability is the absolute value of (standard error of $\log _{10} \mathrm{EC}_{50}$ values)/(mean of $\log _{10} \mathrm{EC}_{50}$ values).
} 
insensitive only to boscalid. Fisher's exact test $(P<0.0001)$ indicated a strong positive association between the sensitivity to penthiopyrad and boscalid.

\section{Discussion}

Determining the baseline sensitivity is the first step in initiating monitoring programs to detect significant shifts in pathogen sensitivity to a fungicide, to predict efficacy of fungicide programs, to recommend appropriate resistance management practices, and to monitor the effectiveness of the recommended practices. This study provides the first report of sensitivity of baseline populations of $D$. bryoniae to the SDHI fungicide penthiopyrad and the DMI fungicides tebuconazole and difenoconazole. Penthiopyrad is a new

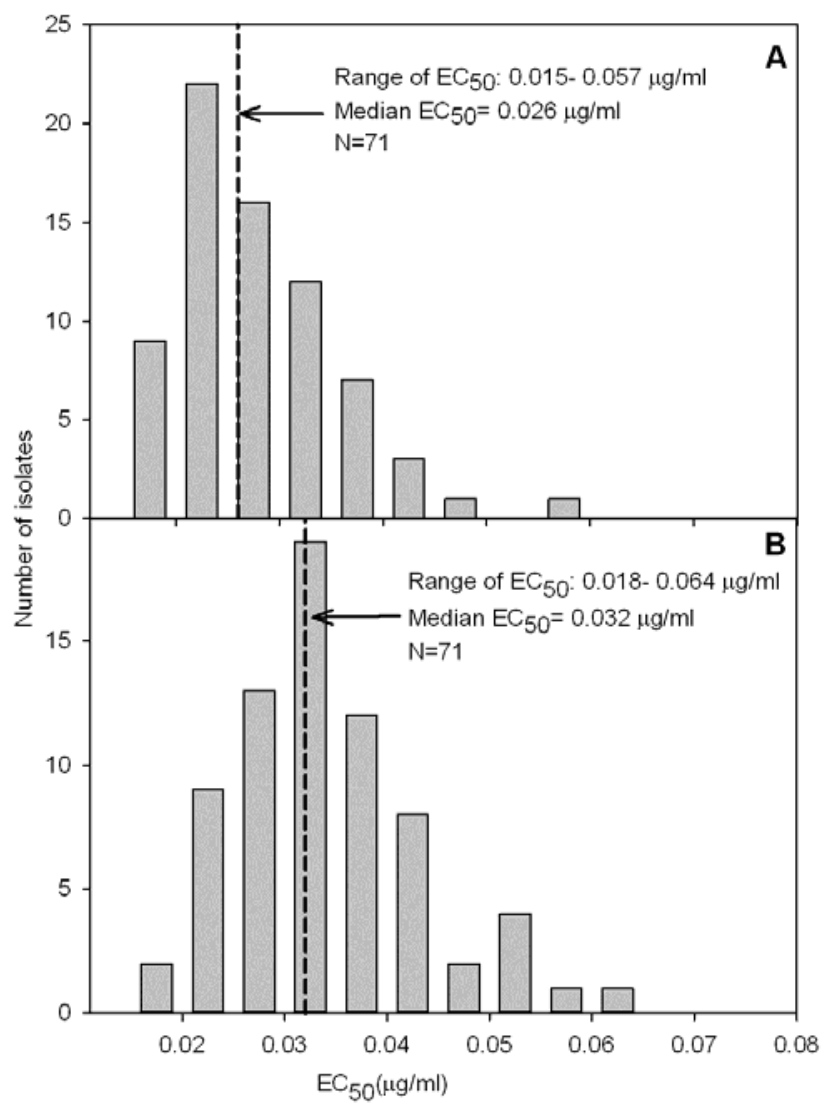

Fig. 1. Frequency distribution of effective concentration at which mycelial growth was inhibited by $50 \%\left(E_{50}\right)$ values for isolates of Didymella bryoniae to $\mathbf{A}$, penthiopyrad and $\mathbf{B}$, boscalid.
SDHI fungicide that has not yet been labeled for use on cucurbits. Tebuconazole and difenoconazole were labeled recently for use on cucurbits and are being widely used by watermelon growers for the management of GSB in Georgia.

Baseline sensitivity to penthiopyrad has been determined for few fungi because it is a relatively new SDHI fungicide. D. bryoniae isolates exhibited a relatively narrow range of $\mathrm{EC}_{50}$ values for penthiopyrad $(0.015$ to $0.057 \mu \mathrm{g} / \mathrm{ml})$ as opposed to the broader range of $\mathrm{EC}_{50}$ values $(0.002$ to $0.30 \mu \mathrm{g} / \mathrm{ml})$ previously reported in Ascochyta rabiei (41). $\mathrm{EC}_{50}$ values to boscalid were estimated for the baseline isolates to determine the relationship between sensitivities to boscalid and penthiopyrad. The range of $\mathrm{EC}_{50}$ values for boscalid was relatively narrow and is consistent with a previous report for $D$. bryoniae (39). The ranges of $\mathrm{EC}_{50}$ values were very similar for both penthiopyrad and boscalid (Table 2). The range of $\mathrm{EC}_{50}$ values for tebuconazole was small and comparable with ranges of $\mathrm{EC}_{50}$ values reported in Colletotrichum cereale (44), Botryosphaeria dothidea (24), and Pyrenophora tritici-repentis (4) and unlike the wider distributions reported in Sclerotinia homoeocarpa (28), Sclerotium rolfsii (11), and Botrytis cinerea (45). The distribution of difenoconazole sensitivity in D. bryoniae isolates was narrow when compared with the distribution reported in Phoma ligulicola (14) and was similar to that reported in Alternaria spp. (29), Cercospora beticola (16), and Colletotrichum coccodes (30). The relatively narrow ranges of $\mathrm{EC}_{50}$ values for DMI fungicides indicate that there may be limited variation within the unexposed $D$. bryoniae population with respect to sensitivity to these fungicides. This may also be due to sensitivity being determined for a small number of isolates collected from only a few counties in southern Georgia. Long-term cold storage also can have an impact on the sensitivity of fungal pathogens to fungicides (8). In most cases of phenotypic instability that have been reported, DMI-resistant isolates tend to become more sensitive following cold storage. This phenomenon could be at least partially responsible for the relatively narrow range of sensitivities to DMIs observed in previously unexposed isolates of $D$. bryoniae that were tested following several years of cold storage. However, effects of cold storage on sensitivity of the baseline isolates of $D$. bryoniae to DMIs are unlikely because resistant isolates have not yet been detected in the field and are unlikely to be present in the stored isolates of $D$. bryoniae that were used to establish baseline sensitivities to tebuconazole and difenoconazole. The sensitivities of all field isolates of $D$. bryoniae were consistent with those of the baseline isolates from storage and all isolates tested so far have been sensitive to the DMIs. The in vitro sensitivity of $D$. bryoniae isolates to these DMI fungicides is also consistent with the excellent control of GSB provided by these fungicides in the field.

Rapid development of resistance to successively introduced fungicides with different modes of action supports Köller's report

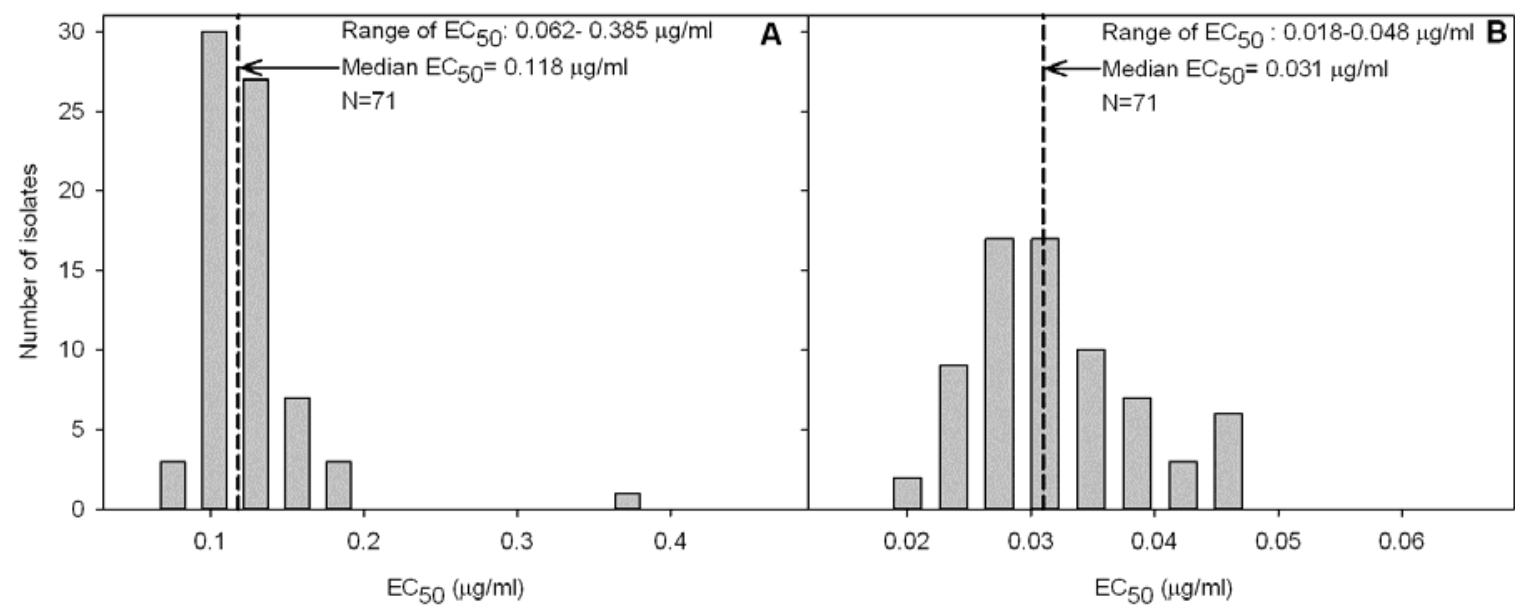

Fig. 2. Frequency distribution of effective concentration at which mycelial growth was inhibited by $50 \%\left(\mathrm{EC}_{50}\right)$ values for isolates of Didymella bryoniae to $\mathrm{A}$, tebuconazole and $\mathbf{B}$, difenoconazole. 
of predisposition of fungicide-resistant isolates to a preferential selection for resistance to other fungicides (21). Monitoring for shifts in sensitivity of $D$. bryoniae isolates to currently effective fungicides should be a high priority because isolates resistant to a fungicide may be prone to accelerated adaptation to another fungicide.

Cross-resistance is common between fungicides belonging to the same chemical class because they share a similar mode of action but is not true in all cases. For example, in the case of SDHI fungicides, a lack of cross-resistance to fluopyram and occurrence of cross-resistance to penthiopyrad in boscalid-resistant isolates was reported in A. alternata (2), Corynespora cassiicola, and Podosphaera xanthii (13). Cross-resistance among DMI fungicides also is not universal. Lack of cross-resistance among some DMIs has been reported in Monilinia oxycocci (27), Mycosphaerella graminicola (26), Ramulispora herpotrichoides (35), Sclerotinia homoeocarpa (12), and Tapesia acuformis (23). Previous reports of an inconsistent relationship between sensitivities to fungicides with a similar mode of action make it clear that we cannot assume the existence of a positive cross-resistance between fungicides of the same chemical class.

This study revealed a significant and positive correlation between sensitivities to boscalid and penthiopyrad within the baseline population. An in vitro sensitivity assay of boscalid-resistant isolates to penthiopyrad revealed a high degree of cross-resistance

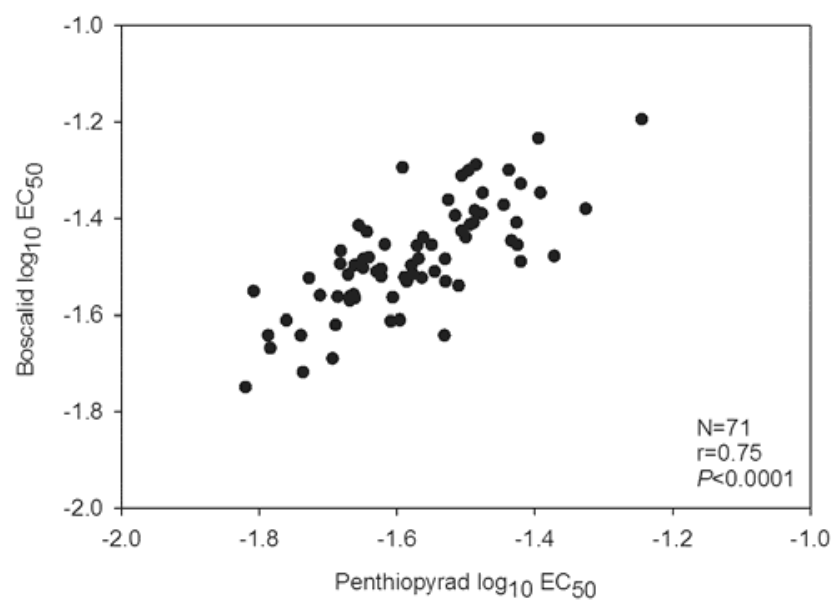

Fig. 3. Correlation between $\log _{10}$-transformed effective concentration at which mycelial growth was inhibited by $50 \%\left(\mathrm{EC}_{50}\right)$ values of isolates of Didymella bryoniae to penthiopyrad and boscalid.

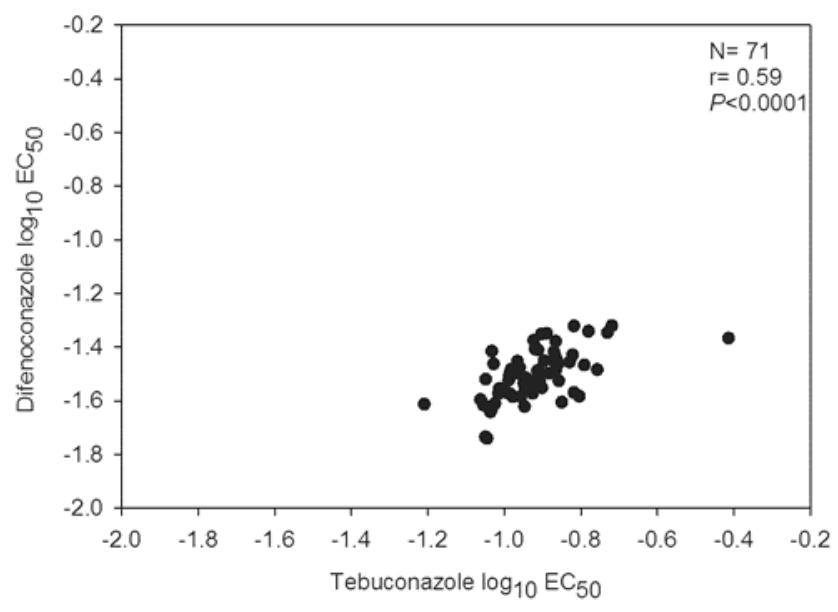

Fig. 4. Correlation between $\log _{10}$-transformed effective concentration at which mycelial growth was inhibited by $50 \%\left(\mathrm{EC}_{50}\right)$ values of isolates of Didymella bryoniae to tebuconazole and difenoconazole. between these two SDHI fungicides and, hence, the use of penthiopyrad for the management of GSB in Georgia, where widespread boscalid-resistance is present (42), may not be a viable option, depending on relative inherent activity of the two fungicides. Weak but statistically significant positive correlations between sensitivities to tebuconazole and difenoconazole were observed for baseline isolates in this study. However, the data set includes a relatively narrow range of sensitivities because $D$. bryoniae isolates resistant to tebuconazole have not yet been observed in Georgia. Therefore, cross-resistance between tebuconazole and difenoconazole could not be determined. Jones and his colleagues (14) reported a wider range of $\mathrm{EC}_{50}$ values for difenoconazole $(0.04$ to $13.8 \mu \mathrm{g} / \mathrm{ml})$ in isolates of Phoma ligulicola that were previously exposed to tebuconazole but not to difenoconazole. This is indirect evidence that cross-resistance exists between these two DMI fungicides in $P$. ligulicola.

Mechanisms responsible for reduced sensitivity to DMIs include alterations in sterol biosynthesis, alterations in the target binding site (CYP51 gene), and changes in fungicide uptake and efflux pump (15). Alteration in the CYP51gene (substitution of isoleucine with valine at codon 381) is reported as one of the mechanisms responsible for reduced sensitivity to azole fungicides in $M$. graminicola and Candida albicans $(6,7,10)$. The study conducted by Fraaije at al. (10) showed that reduced sensitivity to tebuconazole was largely driven by I381V in the CYP51 gene in the $M$. graminicola population. This study also showed that tebuconazole and difenoconazole differentially selected isolates with this type of substitution (I381V). Because evidence of cross-resistance between tebuconazole and difenoconazole has been reported in two other closely related fungi, there is a high probability for cross-resistance between these two DMIs in D. bryoniae. Successive use of these two DMI fungicides in the same spray program may not be a good practice because it may lead to an increased selection of isolates with reduced sensitivity.

In the United States, the labeled rates for application of Folicur and Inspire Super on watermelons are 0.585 liters/ha (tebuconazole $38.7 \%$ a.i.) and 1.17 to 1.46 liters/ha (difenoconazole $8 \%$ a.i.), respectively. Difenoconazole has a fourfold higher intrinsic activity than tebuconazole on mycelial growth of $D$. bryoniae in vitro. This higher intrinsic activity may delay the shift toward reduced sensitivity if difenoconazole is used in the field for the management of GSB. A slight shift in sensitivity to tebuconazole in vitro has been observed in isolates of $D$. bryoniae collected from Florida (data not shown). Because there are no other effective systemic fungicides registered for use for managing GSB in the United States, growers should be cautious about the use of DMIs. Performance of DMI fungicides in replicated fungicide trials and shifts in the in vitro sensitivity of the pathogen population should be closely monitored to predict resistance development and, thus, avoid potential disease control failures. Use of protectant fungicides such as chlorothalonil and mancozeb as rotation partners with a DMI fungicide are expected to help in reducing the selection of isolates less sensitive to DMIs.

\section{Acknowledgments}

We thank B. Evans for technical support and H. Sanders for assistance in collection of fungal isolates.

\section{Literature Cited}

1. Arny, C. J., and Rowe, R. C. 1991. Effects of temperature and duration of surface wetness on spore production and infection of cucumbers by Didymella bryoniae. Phytopathology 81:206-209.

2. Avenot, H. F., and Michailides, T. J. 2010. Progress in understanding molecular mechanisms and evolution of resistance to succinate dehydrogenase inhibiting (SDHI) fungicides in phytopathogenic fungi. Crop Prot. 29:643-651.

3. Avenot, H., Morgan, D. P., and Michailides, T. J. 2008. Resistance to pyraclostrobin, boscalid and multiple resistance to Pristine (pyraclostrobin + boscalid) fungicide in Alternaria alternata causing Alternaria late blight of pistachios in California. Plant Pathol. 57:135-140.

4. Beard, C., Loughman, R., Smith, A., and Speijers, J. 2009. Baseline sensitivity to three triazole fungicides in Pyrenophora tritici-repentis. Australas. Plant Pathol. 38:168-172. 
5. Brent, K. J., and Hollomon, D. W. 2007. Fungicide resistance in crop pathogens: how can it be managed? In: Fungicide Resistance Action Committee Monogr. No.1. Crop Life International, Brussels.

6. Cools, H. J., Fraaije, B. A., and Lucas, J. A. 2005. Molecular examination of Septoria tritici isolates with reduced sensitivities to triazoles. Pages 103114 in: Modern Fungicides and Antifungal Compounds. H.-W. Dehne, U. Gisi, K. H. Kuck, P. E. Russell, and H. H. Lyr, eds. BCPC, Alton, UK.

7. Cools, H. J., Fraaije, B. A., and Lucas, J. A. 2005. Molecular mechanisms correlated with changes in triazole sensitivity in isolates of Mycosphaerella graminicola. Pages 267-274 in: Proc. BCPC Congr. Crop Sci. Technol. BCPC, Alton, UK

8. Cox, D. K., Bryson, K. P., and Schnabel, G. 2007. Instability of propiconazole resistance and fitness in Monilinia fructicola. Phytopathology 97:448453.

9. Délye, C., Laigret, F., and Corio-Costef, M. F. 1997. A mutation in the 14 alpha demethylase gene of Uncinula necator that correlates with resistance to a sterol biosynthesis inhibitor. Appl. Environ. Microbiol. 63:2966-2970.

10. Fraaije, B. A., Cools, H. J., Kim, S-H., Motteram, J., Clark, W. S., and Lucas, J. A. 2007. A novel substitution I381V in the sterol $14 \alpha$-demethylase (CYP51) of Mycosphaerella graminicola is differentially selected by azole fungicides. Mol. Plant Pathol. 8:245-254.

11. Franke, M. D., Brenneman, T. B., Stevenson, K. L., and Padgett, G. B. 1998. Sensitivity of isolates of Sclerotium rolfsii from peanut in Georgia to selected fungicides. Plant Dis. 82:578-583.

12. Hsiang, T., Yang, L., and Barton, W. 1997. Baseline sensitivity and crossresistance to demethylation-inhibiting fungicides in Ontario isolates of Sclerotinia homoeocarpa. Eur. J. Plant Pathol. 103:409-416.

13. Ishii, H., Miyamoto, T., Ushio, S., and Kakishima, M. 2011. Lack of crossresistance to a novel succinate dehydrogenase inhibitor, fluopyram, in highly boscalid-resistant isolates of Corynespora cassiicola and Podosphaera xanthii. Pest Manage. Sci. 67:474-482.

14. Jones, S., Pethybridge, S., Hay, F., Groom, T., and Wilson, C. 2007. Baseline sensitivity of Australian Phoma ligulicola isolates from pyrethrum to azoxystrobin and difenoconazole. J. Phytopathol. 155:377-380.

15. Joseph-Horne, T., and Hollomon, D. W. 1997. Molecular mechanisms of azole resistance in fungi. FEMS Microbiol. Lett. 49:141-149.

16. Karaoglanidis, G. S., and Thanassoulopoulos, C. C. 2003. Cross-resistance patterns among sterol biosynthesis inhibiting fungicides (SBIs) in Cercospora beticola. Eur. J. Plant Pathol. 109:929-934.

17. Keinath, A. P. 2000. Effects of protectant fungicide application schedules on gummy stem blight epidemics and marketable yield of watermelon. Plant Dis. 84:254-260.

18. Keinath, A. P. 2009. Sensitivity to azoxystrobin in Didymella bryoniae isolates collected before and after field use of strobilurin fungicides. Pest Manage. Sci. 65:1090-1096.

19. Keinath, A. P., May, W., III, and DuBose, V. 1999. Effects of number of sequential Quadris applications and companion fungicide on foliar disease of watermelon, 1998. Fungic. Nematicide Tests 54:279.

20. Keinath, A. P., and Zitter, T. A. 1998. Resistance to benomyl and thiophanate-methyl in Didymella bryoniae from South Carolina and New York. Plant Dis. 82:479-484.

21. Köller, W., and Wilcox, W. F. 2001. Evidence for the predisposition of fungicide-resistant phenotypes of Venturia inaequalis to a preferential selection for resistance to other fungicides. Phytopathology 91:776-781.

22. Köller, W., Wilcox, W. F., Barnard, T., Jones, A. L., and Braun, G. 1997. Detection and quantification of resistance of Venturia inaequalis populations to sterol demethylation inhibitors. Phytopathology 87:184-190.

23. Leroux, P., Chapeland, F., Arnold, A., and Gredt, M. 2000. New cases of negative cross-resistance between fungicides, including sterol biosynthesis inhibitors. J. Gen. Plant Pathol. 66:75-81.

24. Ma, Z., Morgan, D. P., Felts, D., and Michailides, T. J. 2002. Sensitivity of Botryosphaeria dothidea from California pistachio to tebuconazole. Crop Prot. 21:829-835

25. Markoglou, A., Malandrakin, A., Vitoratos, A., and Ziogas, B. 2006. Characterization of laboratory mutants of Botrytis cinerea resistant to QoI fungicides. Eur. J. Plant Pathol. 115:149-162.

26. Mavroeidi, V. I., and Shaw, M. W. 2005. Sensitivity distributions and cross-resistance patterns of Mycosphaerella graminicola to fluquinconazole, prochloraz and azoxystrobin over a period of 9 years. Crop Prot. 24:259-266.

27. McManus, P. S., Best, V. M., Voland, R. P., and Leininger, B. L. 1999 Sensitivity of Monilinia oxycocci to fenbuconazole and propiconazole in vitro and control of cranberry cottonball in the field. Plant Dis. 83:445-450.

28. Ok, C.-H., Popko, J. T., Jr., Campbell-Nelson, K., and Jung, G. 2011. In vitro assessment of Sclerotinia homoeocarpa resistance to fungicides and plant growth regulators. Plant Dis. 95:51-56.

29. Olaya, G., Bounds, R., and Tally, A. 2008. Sensitivity to azoxystrobin, difenoconazole and cyprodinil of Alternaria spp. isolates causing Alternaria leaf spot on almonds. (Abstr.) Phytopathology 98:S116.

30. Olaya, G., Cochran, A., and Gudmestad, N. 2010. Difenoconazole baseline sensitivity distribution of Colletotrichum coccodes isolates from potatoes. (Abstr.) Phytopathology 100:S93.

31. Olaya, G., and Holm, A. 2001. Sensitivity of Didymella bryoniae isolates to azoxystrobin. (Abstr.) Phytopathology 91:S67.

32. Parker, D. M., Zhang, N., Smart, C. D., and Köller, W. D. 2006. Polymorphism of 14 alpha-demethylase gene (CYP51) in brown rot pathogen $\mathrm{Mo}$ nilinia fructicola from a resistant orchard in New York State. (Abstr.) Phytopathology. 96:S90.

33. Pasche, J. S., Piche, L. M., and Gudmestad, N. C. 2005. Effect of the F129L mutation in Alternaria solani on fungicides affecting mitochondrial respiration. Plant Dis. 89:269-278.

34. Reynolds, K. L., Brenneman, T. B., and Bertrand, P. F. 1997. Sensitivity of Cladosporium caryigenum to propiconazole and fenbuconazole. Plant Dis. 81:163-166.

35. Robbertse, B., Holz, G., and Crous, P. W. 1996. Sensitivity of South African Ramulispora herpotrichoides isolate to carbendazim and ergosterol biosynthesis inhibitors. Plant Pathol. 45:270-275.

36. Seebold, K., and Langston, D. B., Jr. 2004. Evaluation of fungicides for control of gummy stem blight of watermelon. Fungic. Nematicide Tests 59:140.

37. Sitterly, W. R., and Keinath, A. P. 1996. Gummy stem blight. Pages 27-28 in: Compendium of Cucurbit Diseases. T. A. Zitter, D. L. Hopkins, and C. E. Thomas, eds. American Phytopathological Society, St. Paul, MN.

38. Smith, F. D., Parker, D. M., and Köller, W. 1991. Sensitivity distribution of Venturia inaequalis to sterol demethylation inhibitor flusilazole: Baseline sensitivity and implications for resistance monitoring. Phytopathology 81:392-396.

39. Stevenson, K. L., Langston, D. B., Jr., and Sanders, F. 2008. Baseline sensitivity and evidence of resistance to boscalid in Didymella bryoniae. (Abstr.) Phytopathology 98:S151.

40. Stevenson, K. L., Langston, D. B., Jr., and Seebold, K. W. 2004. Resistance to azoxystrobin in the gummy stem blight pathogen documented in Georgia. Plant Health Progress. Online publication. doi:10.1094/PHP-2004-1207-01RS

41. Thaher, N. H., Gossen, B. D., and McDonald, M. 2010. Baseline sensitivity of Ascochyta rabiei to penthiopyrad, a new SDHI fungicide. (Abstr.) Phytopathology 100:S125.

42. Thomas, A. 2011. Sensitivity of Didymella bryoniae to DMI and SDHI fungicides and the relationship between fungicide sensitivity and control of gummy stem blight in watermelon. M.S. thesis, The University of Georgia, Athens.

43. Van Steekelenburg, N. A. M. 1983. Epidemiological aspects of Didymella bryoniae, the cause of stem and fruit rot of cucumber. Neth. J. Plant Pathol. 89:75-86

44. Wong, F. P., and Midland, S. L. 2007. Sensitivity distributions of California populations of Colletotrichum cereale to the DMI fungicides propiconazole, myclobutanil, tebuconazole, and triadimefon. Plant Dis. 91:1547-1555.

45. Zhang, C., Zhu, J., Wei, F., Liu, S., and Zhu, G. 2007. Sensitivity of Botrytis cinerea from greenhouse vegetables to DMIs and fenhexamid. Phytoparasitica 35:300-313. 